\title{
Analysis of Longitudinal follow-up Data of Physical Growth in Singleton Full- Term Small for Gestational Age Infants
}

\author{
Yan Zhao \\ Chongqing Health Center for Women and Children \\ Xin Fan ( 649046880@qq.com ) \\ Chongqing Health Center for Women and Children \\ Jing Wen \\ Chongqing Health Center for Women and Children \\ Wenling Gan \\ Chongqing Health Center for Women and Children \\ Guiyuan Xiao \\ Chongqing Health Center for Women and Children
}

\section{Research article}

Keywords: full-term infants, singleton, small gestational age, catch-up growth, Z score

Posted Date: February 19th, 2021

DOI: https://doi.org/10.21203/rs.3.rs-244809/v1

License: @ (i) This work is licensed under a Creative Commons Attribution 4.0 International License. Read Full License

Version of Record: A version of this preprint was published at Journal of International Medical Research on December 1st, 2021. See the published version at https://doi.org/10.1177/03000605211060672. 


\begin{abstract}
Background: The rate of full-term small for gestational age (SGA) infants is rising worldwide. This study aimed to investigate the catch-up growth pattern of singleton full-term SGA infants in the first of the year.
\end{abstract}

Methods A single-center retrospective study assessed singleton full-term SGA infants was admitted to the Department of Child Health Care, Chongqing Health Center for Women and Children from August 2015 to December 2018. Weight, length and head circumference were measured at birth, 1 month, 3 months, 6 months and 12 months of age. The Z-score was evaluated.

Results A total 210 SGA infants were included in this study. Boys $(n=90)$ and girls $(n=120)$ showed comparable gestational ages, and birth weights and lengths. Weight, length and head circumference in SGA infants of all age groups were increased, with the fastest growth stage from birth to 3 months. The speeds of weight and head circumference catch-up were higher than that of body length. Birth length was not related to parents' heights in both genders. At 12 months, there were significant associations of body length with father's height, mother's height and parents' heights in boys; in girls, body length showed associations with mother's height and parents' heights.

Conclusions Full-term SGA infants grow rapidly after birth, with the fastest growth rate in the first three months as examined by weight, length and head circumference. Within 12 months after birth, catch-up was better for weight compared with length. Finally, body length in SGA infants was positively correlated with the parents' heights at 12 months.

\title{
Background
}

Small for gestational age (SGA) is a term used to characterize newborns whose birth weight is below the 10th percentile of the birth weight or less than 2 standard deviations from the average birth weight of the same gestational age and sex[1, 2]. SGA infants are classified into the constitutionally normal infants and those that underwent growth restriction[3,4]. The first group of infants show normal birth weight below the 10th percentile due to inherent parameters, including maternal height and/or weight, ethnicity and parity, with no elevated risk of perinatal mortality or morbidity[5]. The second group includes infants with fetal growth restriction (FGR), which is not synonymous with SGA although these two terms are commonly employed interchangeably[6].

A 2010 survey reported about 32.4 million SGA infants born in 138 low- and middle-income nations, representing $27 \%$ of all livebirths, including 10.6 million full-term babies[7]. According to the above report, China had an incidence of SGA approximating 6.5\%, ranking fifth among the examined countries[7]. Another survey performed in China showed that $9.10 \%-10.13 \%$ of infants are SGA, with a mortality rate of $2.45 \%$, which is significantly higher than the overall neonatal mortality rate $(1.20 \%)$ recorded in the same period[8].

Based on the high incidence of SGA, special attention should be paid to this pathology. The risk factors for and complications of SGA are well-studied. For example, SGA causes neonatal hypoglycemia and hyperbilirubinemia, and it was suggested that perinatal monitoring and antenatal care should be strengthened to decrease SGA incidence and perinatal complications[9]. However, it remains unclear whether and when SGA infants can show growth catchup. Therefore, the present study aimed to investigate the catch-up growth pattern of singleton SGA infants within 12 months after birth. The results revealed that full-term SGA infants grow rapidly after birth, especially in the first three months. In addition, catch-up was better for weight compared with length in the first year of life in SGA infants.

\section{Methods}

\section{Study design and participants}

This study retrospectively assessed singleton full-term newborns with SGA based on the 2013 FENTON curve[10] in the Department of Child Health Care, Chongqing Health Center for Women and Children from August 2015 to December 2018. Inclusion criteria were: (1) gestational age (GA) $\geq 37$ weeks and < 42 weeks; (2) birth weight < 10th percentile in the same gender. Exclusion criteria were: (1) hereditary endocrine disease; (2) significant obvious mental retardation; (3) parents with a family history of mental, genetic and/or metabolic diseases.

This study was approved by the Ethics Committee of Chongqing Health Center for Women and Children and the requirement for informed consent was waived.

\section{Data Collection}

The birth weights, lengths and gestational ages of the infants were obtained from medical birth certificates; weights, lengths and head circumferences were measured during regular follow-up visits at the Child Health Care Department of Chongqing Maternal and Child Health Hospital.

All measurements were performed by two trained nurses in our department's measurement room. The weight was measured with a sitting and horizontal lever scale at an accuracy of $10 \mathrm{~g}$. Body length was measured with a standard measuring bed in the supine position at an accuracy of $0.1 \mathrm{~cm}$. Head circumference was assessed with a soft ruler at an accuracy of $0.1 \mathrm{~cm}$.

\section{Catch-up Growth Evaluation}


Catch-up growth was evaluated by measuring heights, weights, and head circumferences at the ages of 1, 3, 6, and 12 months, respectively, during the followup period according to the 2006 World Health Organization Children's Growth Standards[11].

\section{Statistical analysis}

The SPSS 15.0 statistical software (SPSS Inc., Chicago, IL, USA) was used for statistical analysis. Normally distributed continuous data were expressed as mean \pm standard deviation (SD), and assessed by t-test. Categorical variables were expressed as $\mathrm{n}(\%)$, and compared by the chi-square test. Z-scores was calculated, which equaled to (the measured values - mean)/SD. Pearson correlation analysis was performed to examine associations of height in full-term SGA infants with those of their parents. $\mathrm{P}<0.05$ was considered statistically significant.

\section{Results}

\section{General birth conditions}

Totally 210 full-term infants with a gestational age $\geq 37$ weeks and $<42$ weeks were SGA, including 90 males and 120 females. Average gestational age was $37.58 \pm 0.84$ weeks, with $37.43 \pm 0.75$ and $37.69 \pm 0.89$ weeks in boys and girls, respectively. Average birth weight was $2310 \pm 170 \mathrm{~g}$, with $2320 \pm 178$ and 2306 $\pm 176 \mathrm{~g}$ in boys and girls, respectively. Average length was $46.44 \pm 1.71 \mathrm{~cm}$, with $46.33 \pm 1.76$ and $46.51 \pm 1.67 \mathrm{~cm}$ in boys and girls, respectively. The average height of the fathers was $171.40 \pm 5.12 \mathrm{~cm}$, with $171.57 \pm 4.58$ and $171.22 \pm 5.33 \mathrm{~cm}$ for boys and girls, respectively. The average height of the mothers was $158.51 \pm 4.44 \mathrm{~cm}$, with $158.31 \pm 4.98$ and $158.66 \pm 3.40 \mathrm{~cm}$ for boys and girls, respectively. There were no statistically significant differences in these values between SGA boys and girls (Table 1).

Table 1

Birth statuses and parent heights of full-term infants of both genders

\begin{tabular}{|lllll|}
\hline Subjects & Boys & Girls & Total & P \\
& $\mathbf{N}=90$ & $\mathbf{N}=\mathbf{1 2 0}$ & $\mathbf{N}=\mathbf{2 1 0}$ & \\
\hline Average birth weight $(\mathrm{g})$ & $2297.07 \pm 283.70$ & $2306.38 \pm 161.11$ & $2306.3 \pm 161.11$ & 0.7 \\
\hline Average birth height $(\mathrm{cm})$ & $46.23 \pm 1.76$ & $46.52 \pm 1.67$ & $46.44 \pm 1.71$ & 0.43 \\
\hline Gestational age (week) & $37.43 \pm 0.75$ & $37.69 \pm 0.89$ & $37.58 \pm 0.84$ & 0.11 \\
\hline Father's average height $(\mathrm{cm})$ & $171.57 \pm 4.58$ & $171.22 \pm 5.33$ & $171.40 \pm 5.12$ & 0.69 \\
\hline Mother's average height $(\mathrm{cm})$ & $158.31 \pm 4.98$ & $158.66 \pm 3.40$ & $158.51 \pm 4.44$ & 0.57 \\
\hline All data showed as mean \pm SD. & & & & \\
\hline
\end{tabular}

\section{Z scores}

Next, average Z scores and Z value distributions of the study subjects were examined at 1, 3, 6, and 12-months for body length, weight, and head circumference. All indicators steadily increased with age; full-term infants of both genders showed increased Z scores compared with the corresponding birth values (Fig. 1).

The average $Z$ scores of various indicators in children of different ages all showed different rates of growth. As shown in Table 2, all indicators had the most significant growth in the first three months after birth. Both male and female babies showed faster increase in weight compared with length and head circumference (Table 2). 
Table 2

Z-scores of different genders and ages, and their distributions

\begin{tabular}{|c|c|c|c|c|c|c|c|c|c|c|c|c|c|c|}
\hline \multirow{2}{*}{\multicolumn{2}{|c|}{$\begin{array}{l}\text { Age } \\
\text { (months) }\end{array}$}} & \multicolumn{2}{|c|}{ Z score of weight } & \multicolumn{7}{|c|}{ Z score of length } & \multicolumn{4}{|c|}{ Z score of head circumference } \\
\hline & & $M \pm S D$ & \multirow[t]{2}{*}{ Mean } & \multicolumn{3}{|c|}{ Percentage\% } & \multirow{2}{*}{$\begin{array}{l}M \pm \\
S D\end{array}$} & \multirow{2}{*}{ Mean } & \multicolumn{2}{|c|}{ Percentage\% } & \multicolumn{2}{|l|}{$\mathrm{M} \pm \mathrm{SD}$} & \multirow{2}{*}{ Mean } & \multirow{2}{*}{$\begin{array}{c}\mathrm{PeI} \\
<-4\end{array}$} \\
\hline & & & & $<-2$ & $-2-0>0$ & & & & $<-2$ & $-2-0$ & $\overrightarrow{0}$ & & & \\
\hline \multirow[t]{2}{*}{0} & Male & $\begin{array}{l}1.79 \\
\pm \\
0.63\end{array}$ & -1.85 & $58(58.59)$ & 0 & 0 & $\begin{array}{l}-1.83 \\
\pm \\
0.93\end{array}$ & -2.00 & $47(52.22)$ & $39(43.33)$ & $4(4.44)$ & & - & - \\
\hline & Female & $\begin{array}{l}1.65 \\
\pm \\
0.71\end{array}$ & -1.79 & $79(65.83)$ & 0 & 0 & $\begin{array}{l}-1.39 \\
\pm \\
0.90\end{array}$ & -1.66 & $31(25.83)$ & 88(73.33) & $1(0.84)$ & & - & - \\
\hline \multirow[t]{2}{*}{1} & Male & $\begin{array}{l}1.47 \\
\pm \\
0.65\end{array}$ & -1.50 & 16(17.78) & 73(81.11) & $1(1.11)$ & $\begin{array}{l}-1.71 \\
\pm \\
0.98\end{array}$ & -1.75 & $36(40.00)$ & $52(57.78)$ & $2(2.22)$ & $\begin{array}{l}-0.81 \\
\pm \\
0.90\end{array}$ & -0.68 & $7(7$ \\
\hline & Female & $\begin{array}{l}1.10 \\
\pm \\
0.74\end{array}$ & -1.17 & 11(9.17) & $99(82.50)$ & $10(8.33)$ & $\begin{array}{l}-1.26 \\
\pm \\
0.81\end{array}$ & -1.36 & 28(23.33) & $84(70.00)$ & $8(6.66)$ & $\begin{array}{l}-0.85 \\
\pm \\
2.45\end{array}$ & -0.60 & $7(5$ \\
\hline \multirow[t]{2}{*}{3} & Male & $\begin{array}{l}0.64 \\
\pm \\
0.93\end{array}$ & -0.75 & $6(6.67)$ & $63(70.00)$ & $21(23.33)$ & $\begin{array}{l}-1.09 \\
\pm \\
1.13\end{array}$ & -1.05 & $20(22.22)$ & $53(58.88)$ & 17(18.89) & $\begin{array}{l}-0.66 \\
\pm \\
1.06\end{array}$ & -0.42 & $7(7$ \\
\hline & Female & $\begin{array}{l}0.52 \\
\pm \\
0.73\end{array}$ & -0.50 & $4(2.50)$ & $86(71.67)$ & $30(25.00)$ & $\begin{array}{l}-0.88 \\
\pm \\
0.94\end{array}$ & -0.95 & $13(10.83)$ & $88(73.33)$ & $19(15.83)$ & $\begin{array}{l}-0.63 \\
\pm \\
0.86\end{array}$ & -0.64 & $5(4$ \\
\hline \multirow[t]{2}{*}{6} & Male & $\begin{array}{l}0.49 \\
\pm \\
0.93\end{array}$ & -0.56 & $5(5.56)$ & $58(64.44)$ & $27(30.00)$ & $\begin{array}{l}-1.01 \\
\pm \\
0.94\end{array}$ & -0.95 & 15(16.67) & $62(68.89)$ & $13(14.44)$ & $\begin{array}{l}-0.60 \\
\pm \\
1.03\end{array}$ & -0.57 & $4(4$ \\
\hline & Female & $\begin{array}{l}0.39 \\
\pm \\
0.81\end{array}$ & -0.44 & $0(0)$ & $81(67.50)$ & $39(32.50)$ & $\begin{array}{l}-0.59 \\
\pm \\
0.85\end{array}$ & -0.66 & $5(4.17)$ & $90(75.00)$ & $25(20.83)$ & $\begin{array}{l}-0.45 \\
\pm \\
0.85\end{array}$ & -0.46 & $4(3$ \\
\hline \multirow[t]{2}{*}{12} & Male & $\begin{array}{l}0.50 \\
\pm \\
0.79\end{array}$ & -0.50 & $3(3.33)$ & $53(58.89)$ & $34(37.78)$ & $\begin{array}{l}-0.99 \\
\pm \\
1.05\end{array}$ & -0.93 & 17(18.89) & $57(63.33)$ & 16(17.78) & $\begin{array}{l}-0.53 \\
\pm \\
0.99\end{array}$ & -0.47 & $5(5$ \\
\hline & Female & $\begin{array}{l}0.33 \\
\pm \\
0.74\end{array}$ & -0.50 & $1(0.83)$ & $81(67.50)$ & $38(31.67)$ & $\begin{array}{l}-0.55 \\
\pm \\
0.58\end{array}$ & -0.58 & $7(5.83)$ & $81(67.50)$ & $32(26.67)$ & $\begin{array}{l}-0.36 \\
\pm \\
0.85\end{array}$ & -0.47 & $1(C$ \\
\hline
\end{tabular}

In this study, the $Z$ scores distribution of the children at 1, 3, 6, and 12-month-old in body length, weight and head circumference were analyzed. The percentage of full-term SGA infants at 0, 1, 3, 6 and 12 months, whose Z score <-2 were: boys: full-term SGA weights were (58.59\%, $17.78 \%, 6.67 \%, 5.56 \%$, $3.33 \%)$, body lengths were $(52.22 \%, 40.00 \%, 22.22 \%, 16.67 \%, 18.89 \%)$ and head circumferences were $(-, 7.78 \%, 7.78 \%, 4.44 \%, 5.55 \%)$ respectively; girls: fullterm SGA weights were $(65.83 \%, 9.17 \%, 2.50 \%, 0 \%, 0.83 \%)$, the lengths were $(25.83 \%, 23.33 \%, 10.83 \%, 4.17 \%, 5.83 \%)$ and the head circumferences were $(-$, $5.83 \%, 4.17 \%, 3.33 \%, 0.83 \%)$ (Table 2$)$.

\section{Associations of length and height in full-term SGA infants below 12 months of age with parents' heights}

Birth length in boys and girls was not correlated to parents' heights (Fig. 2). At 12 months of age, Pearson correlation coefficients between height in SGA boys and father's, mother's and parents' combined heights, respectively, were $0.397,0.484$, and 0.565 , all of which were statistically significant, indicating a moderately strong correlation. Therefore, the greater the parents' heights, the higher the boy's height at 12 months of age. In girls, Pearson correlation coefficients between the child height at 12 months and the mother's and parents' combined heights were 0.188 and 0.199 , respectively, with statistical significance for these low correlations. These data indicated that the greater the mother's or parents' combined height, the higher girl's height at 12 months of age. There was no significant correlation between the father's height and girl's height at the age of 12 months. These data are summarized in Table 3 . 
Table 3

Associations of child's body lengths with parents' heights

\begin{tabular}{|c|c|c|c|c|}
\hline & & Father's height vs child's length & Mother's height vs child's length & Parent's height vs child's length \\
\hline \multicolumn{5}{|c|}{ Birth length } \\
\hline & Male & $-0.045(0.678)$ & $0.038(0.720)$ & $-0.004(0.973)$ \\
\hline & Female & $-0.068(0.462)$ & $0.070(0.450)$ & $-0.011(0.908)$ \\
\hline \multicolumn{5}{|c|}{ 12-month-old } \\
\hline \multirow[t]{2}{*}{ Length } & Male & $0.397(<0.001)$ & $0.484(<0.001)$ & $0.565(<0.001)$ \\
\hline & Female & $0.149(0.108)$ & $0.188(0.042)$ & $0.199(0.031)$ \\
\hline
\end{tabular}

After categorizing the father's, mother's and combined parents' heights (short, middle and tall groups, respectively), analysis of variance was performed to assess potential differences in the heights of SGA infants at the age of 12 months. Among boys, there were significant differences in father, mother, and combined parents' heights in all the above subgroups. However, no significant differences were found among girls (Table 4). 
Table 4

Associations of body length of different genders with the heights of parents grouped by weight.

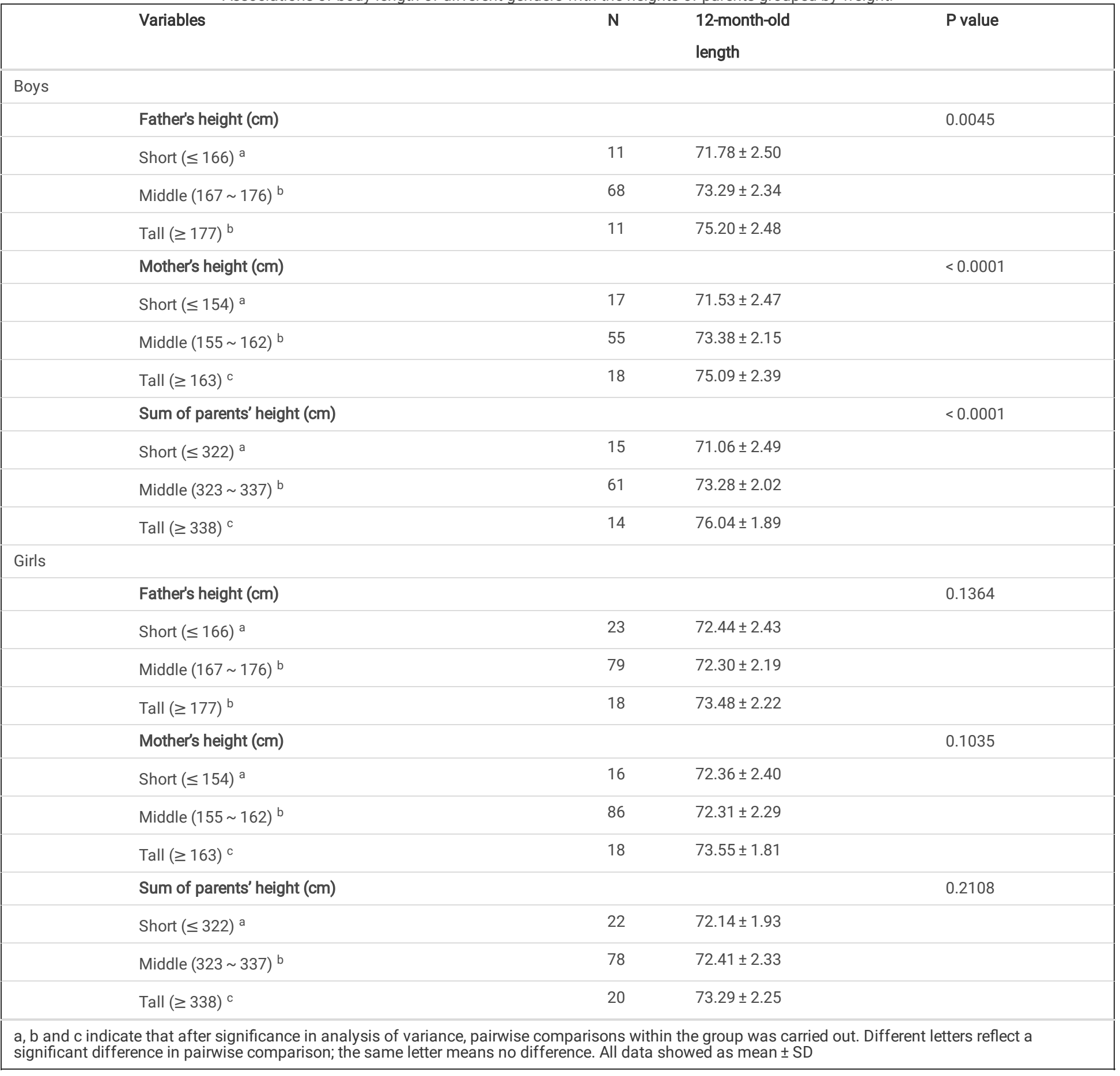

\section{Discussion}

The present study demonstrated that full-term SGA infants grow rapidly upon birth, especially in the first three months of life. In addition, catch-up was better for weight compared with length in the first year of life in SGA infants.

The definition of small for gestational age has been controversial so far. As a standard, this study used the INTERGROWTH-21st project, which assessed data in 8 middle and high-income countries[12]. Although no statistically significant differences were found among the 8 nations, using this standard in other countries or regions may reveal differences. A study in Hong Kong, China[13] showed that when the INTERGROWTH-21st standard is employed to determine birth weight in infants, the proportion of SGA infants is greatly increased compared with local standards. Therefore, a different diagnosis can be obtained for the same baby just because of differences in diagnostic criteria. Although China established a birth weight curve for newborns with different gestational ages in 2015[14], it is not convenient to determine full-term small-fetal weights at different gestational ages since these data do not provide a standard for length in newborns based on gestational age. We assessed infant lengths within one year after birth, and the above standard was not appropriate for this study. In order to define SGA more reasonably in China, the birth weight and length curves of newborns of different gestational ages should be generated as soon as 
possible, so that clinicians can make a more accurate assessment of birth conditions in order to facilitate SGA diagnosis. This would improve future follow-up and interventions.

Considering that the birth weights of twins are generally different from those of singletons, only singletons full-term SGA babies were examined according to the INTERGROWTH-21st standard. It is challenging to assess birth head circumference. Therefore, we compared the birth lengths of 210 full-term infants with matched sex and age, and found different $Z$ scores distributions. As shown above, the percentages of boys and girls whose $Z$ scores were less than - 2 were higher than those of counterparts with Z scores below - 2. This indicates that defining SGA based on birth weight alone does not fully reflect the intrauterine development level. Therefore, the 2007 International Pediatric Endocrinology Society and the Growth Hormone Research Society[15], as well as the 2011 Latin American Consensus[16] both adopted the following definition for SGA infants: newborns whose crown and heel lengths are 2SD lower than the average values for newborns of the same gestational age. However, due to the low operability of body length measurement at birth, its accuracy is relatively lower compared with weight assessment, making birth weight more clinically relevant. However, attention should be paid to the assessment of birth length in the clinical evaluation of children under gestational age. We should also pay enough attention to those without low birth weight but showing birth length $2 \mathrm{SD}$ lower than average, strengthening long-term follow-up.

Bocca-Tjeertes et al.[17]followed up full-term SGA infants, and found that catch-up growth is mainly completed during infancy. A prospective study with birth weight $\leq 10$ th percentile of the same gestational age defined as SGA[18] found that $60 \%$ of full-term infants younger than gestational age complete catch-up at 1 year of age. A study showed that the best growth trajectory for full-term SGA infants is to catch up to the 30th percentile in the first few months, and then to a milder catch up speed, reaching the 50th percentile at the age of 7 years and maintaining that level[19]. This study performed a one-year follow-up monitoring of the growth and development of 210 singleton full-term infants smaller than matched gestational age babies in the first year after birth, and measured their 1, 3, 6, and 12-month-old body lengths, weights and head circumferences. Average Z scores for various indicators in full-term infants of both genders after birth continuously increased at various months of age. Most SGA infants showed rapid growth. Although growth rates were different in both genders, growth in the first three months was the most significant in all infants. In addition, boys and girls both showed a faster increase in weight compared with length and head circumference. The rates of body weights, lengths and head circumferences 2SDs below averages at 12 months of age were $1.90 \%$, $10.48 \%$, and $2.86 \%$, respectively. This corroborated findings by Karlberg and Albertsson-Wikland[20]. Studies used weight, body length and head circumference for evaluation, with catch-up growth defined as the corresponding physical index Z scores increasing by $>0.67$ [21]. Full-term SGA babies tend to have rapid catch-up growth after birth. Although the definition of full-term SGA babies uses birth weight, the core of their catch-up growth lies in height. The international consensus[22] defines catch-up growth as a growth rate (cm/year) greater than the median of children of the same age and sex; alternatively, the child's length (height) exceeding those of matched age and sex counterparts can be considered to reach catch-up growth at the 3rd percentile or -2 standard deviation. A recent study by Shi et al.[23] demonstrated that in full-term SGA infants, catch-up growth is maintained at more than $2 \mathrm{~cm}$ in the first few months, from < P10 to P3 P25-p50, with a median catch-up maintained until age 2. It may be optimal to catch up with such growth trajectory and minimize the risk of adverse health consequences for children. Therefore, more attention should be paid to the length of full term SGA infants. Full term SGA infants have specific growth and development patterns, and catch up growth within 6 months is independent of feeding patterns and average daily energy intake[24]. A 2006 WHO study in developing and developed countries confirmed that the nutritional needs of SGA infants are similar to those of counterparts with appropriate for gestational age (AGA). Therefore, feeding strategies for children younger than gestational age should mainly be based on gestational age rather than birth weight; this should not only promote moderate growth, especially linear growth, to ensure a good nervous system outcome, but also avoid overfeeding to reduce the risk of long-term metabolic syndrome[25].

When assessing the growth level of children, the potential effects of genetic factors should be considered. In this study, body lengths at birth and 12 months of age in full-term SGA infants of both genders were analyzed in relation to father's, mother's, and combined parents' heights. As shown above, there was no associations of birth length in boys and girls with father's height, mother's height, and combined parents' heights. However, at the age of 12 months, Pearson correlation coefficients between height and father's, mother's and parents' heights were $0.397,0.484$, and 0.565 in boys, respectively, with statistical significance, indicating that the parents' heights affected child height. The greater the sum of parents' heights, the higher the boy's height at 12 months of age. Among girls, Pearson correlation coefficients between child height and mother's and combined parents' heights were 0.188 and 0.199 , respectively, indicating that the greater the mother's and combined parents' heights, the greater the girl's height at 12 months of age. This is consistent with the positive correlation between the height of the offspring and those of parents in the normal population.

This study had limitations. First, its retrospective design carries inherent shortcomings. In addition, the sample size was relatively small, which may explain why correlations between child and parents' heights in full-term infants of both genders had different coefficients. Finally, the study was performed in a single institution, and the findings have limited generalizability.

\section{Conclusions}

In summary, the physical growth of full-term infants younger than gestational age within 1 year showed a catch-up pattern, with the first 3 months showing the fastest rate. However, the catch-up speeds of weight and body length were not balanced in this study. These findings indicate that child height matters. Therefore, in actual clinical work, the growth and development levels of full-term infants should be assessed based on developmental and genetic characteristics. This is also the basis for developing improved individualized guidance and intervention.

\section{Abbreviations}

SGA, small for gestational age

AGA, appropriate for gestational age 


\section{Declarations}

\section{Ethics approval and consent to participate}

This study was approved by the Ethics Committee of Chongqing Health Center for Women and Children and the requirement for informed consent was waived. All patients signed a surgical consent form and parental consent was obtained in the study.

\section{Consent for publication}

Consent for publication is not applicable since patient records/information was anonymized and de-identified prior to analysis.

\section{Availability of data and materials}

The data set supporting the results of this article are included within the article. The datasets used and/or analysed during the current study are available from the corresponding author on reasonable request.

\section{Competing interests}

The authors declare that they have no conflict of interest.

\section{Funding}

None.

\section{Authors' contributions}

XF contributed to the conception of the study. YZ performed the data analyses and wrote the paper. JW and WLG carried out the data collection. GYX helped statistical analysis. All authors reviewed the results and approved the final version of the manuscript.

\section{Acknowledgements}

Not applicable.

\section{References}

1. Schlaudecker EP, Munoz FM, Bardají A, Boghossian NS, Khalil A, Mousa H, Nesin M, Nisar MI, Pool V, Spiegel HML, et al. Small for gestational age: Case definition \& guidelines for data collection, analysis, and presentation of maternal immunisation safety data. Vaccine. 2017;35:6518-28.

2. Hadar O, Sheiner E, Wainstock T. The Association between Delivery of Small-for-Gestational-Age Neonate and Their Risk for Long-Term Neurological Morbidity. Journal of clinical medicine. 2020;9.

3. Hutcheon JA, Jacobsen GW, Kramer MS, Martinussen M, Platt RW. Small Size at Birth or Abnormal Intrauterine Growth Trajectory: Which Matters More for Child Growth? American journal of epidemiology. 2016;183:1107-13.

4. Hiersch L, Melamed N. Fetal growth velocity and body proportion in the assessment of growth. American journal of obstetrics and gynecology. 2018;218:S700-S711.e701.

5. Şahin Uysal N, Gülümser Ç, Bilgin Yanık F. Maternal and perinatal characteristics of small-for-gestational-age newborns: Ten-year experience of a single center. Journal of the Turkish German Gynecological Association. 2017;18:90-5.

6. Sharma D, Shastri S, Sharma P. Intrauterine Growth Restriction: Antenatal and Postnatal Aspects. Clinical medicine insights. Pediatrics. 2016;10:67-83.

7. Lee AC, Katz J, Blencowe H, Cousens S, Kozuki N, Vogel JP, Adair L, Baqui AH, Bhutta ZA, Caulfield LE, et al. National and regional estimates of term and preterm babies born small for gestational age in 138 low-income and middle-income countries in 2010. The Lancet Global health. 2013;1:e26-36.

8. Shao Xiaomei YH, Xiaoshan Q. Practical Neonatology M4 Edition Beijing. People's Medical Publishing House. 2011.

9. Liu Q, Yang H, Sun X, Li G. Risk factors and complications of small for gestational age. Pakistan journal of medical sciences. 2019;35:1199-203.

10. Fenton TR, Kim JH. A systematic review and meta-analysis to revise the Fenton growth chart for preterm infants. BMC Pediatr. 2013;13:59.

11. Organization WH. The WHO Growth Charts DB/OL I http://www.who.int/childgrowth/standards/en/2006.

12. Papageorghiou AT, Kennedy SH, Salomon LJ, Altman DG, Ohuma EO, Stones W, Gravett MG, Barros FC, Victora C, Purwar M, et al. The INTERGROWTH21 (st) fetal growth standards: toward the global integration of pregnancy and pediatric care. American journal of obstetrics gynecology. 2018;218:630s640.

13. Cheng Y, Leung TY, Lao T, Chan YM, Sahota DS. Impact of replacing Chinese ethnicity-specific fetal biometry charts with the INTERGROWTH-21(st) standard. BJOG: an international journal of obstetrics gynaecology. 2016;123(Suppl 3):48-55.

14. Zhu Li ZR, Zhang S. Development of the birth weight curve of newborns of different gestational ages in China. Chinese Journal of Pediatrics. 2015;53:97-103.

15. Yadav S, Rustogi D. Small for gestational age: growth and puberty issues. Indian pediatrics. 2015;52:135-40. 
16. Boguszewski MC, Mericq V, Bergada I, Damiani D, Belgorosky A, Gunczler P, Ortiz T, Llano M, Domené HM, Calzada-León R, et al. Latin American consensus: children born small for gestational age. BMC Pediatr. 2011;11:66.

17. Bocca-Tjeertes IF, Reijneveld SA, Kerstjens JM, de Winter AF, Bos AF. Growth in small-for-gestational-age preterm-born children from 0 to 4 years: the role of both prematurity and SGA status. Neonatology. 2013;103:293-9.

18. Huang L, Yang S, Yang F, Xiong F. A prospective study about physical growth of children from birth to 2 years old born full-term small-for-gestational-age. J Paediatr Child Health. 2019;55:199-204.

19. Lei X, Chen Y, Ye J, Ouyang F, Jiang F, Zhang J. The optimal postnatal growth trajectory for term small for gestational age babies: a prospective cohort study. J Pediatr. 2015;166:54-8.

20. Karlberg J, Albertsson-Wikland K. Growth in full-term small-for-gestational-age infants: from birth to final height. Pediatr Res. 1995;38:733-9.

21. Batista RF, Silva AA, Barbieri MA, Simões VM, Bettiol H. Factors associated with height catch-up and catch-down growth among schoolchildren. PloS one. 2012;7:e32903.

22. Fang Fang ZJ, Jiang F. Pay attention to the cause identification and growth management of small for gestational age infants. Chinese Journal of Pediatrics. 2019;57:660-2.

23. Shi H, Yang X, Wu D, Wang X, Li T, Liu H, Guo C, Wang J, Hu X, Yu G, et al. Insights into infancy weight gain patterns for term small-for-gestational-age babies. Nutrition journal. 2018;17:97.

24. Yang Q, Cheng Q, Zhang X. [Relationship between energy intake and catch-up growth in full-term small-for-gestational-age infants under 6 months of age]. Zhonghua er ke za zhi = Chinese. journal of pediatrics. 2015;53:919-24.

25. Tudehope D, Vento M, Bhutta Z, Pachi P. Nutritional requirements and feeding recommendations for small for gestational age infants. J Pediatr. 2013;162:81-9.

\section{Figures}

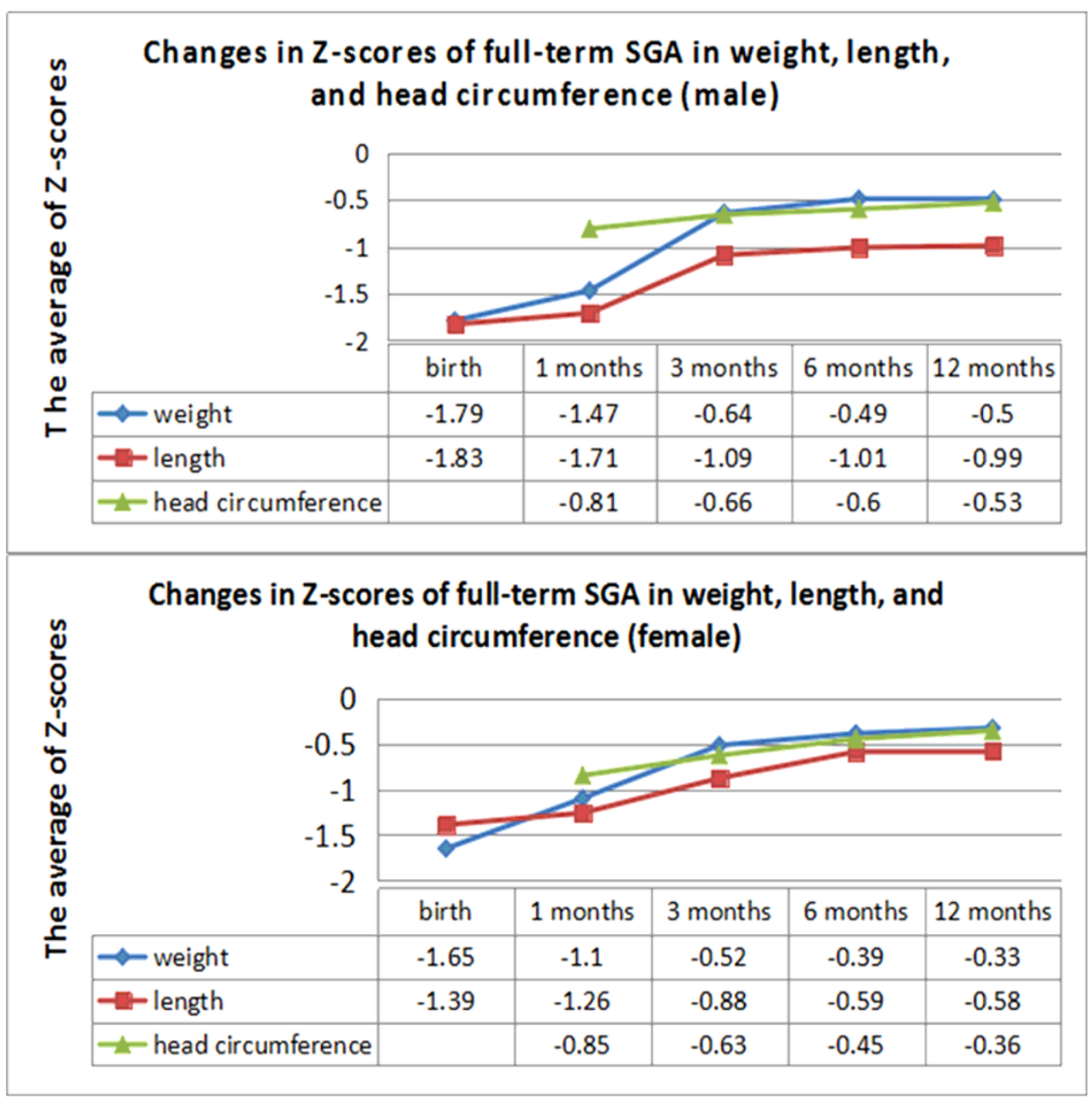

Figure 1

Z-scores for weight, length and head circumference. (A) Boys. (B) Girls. 

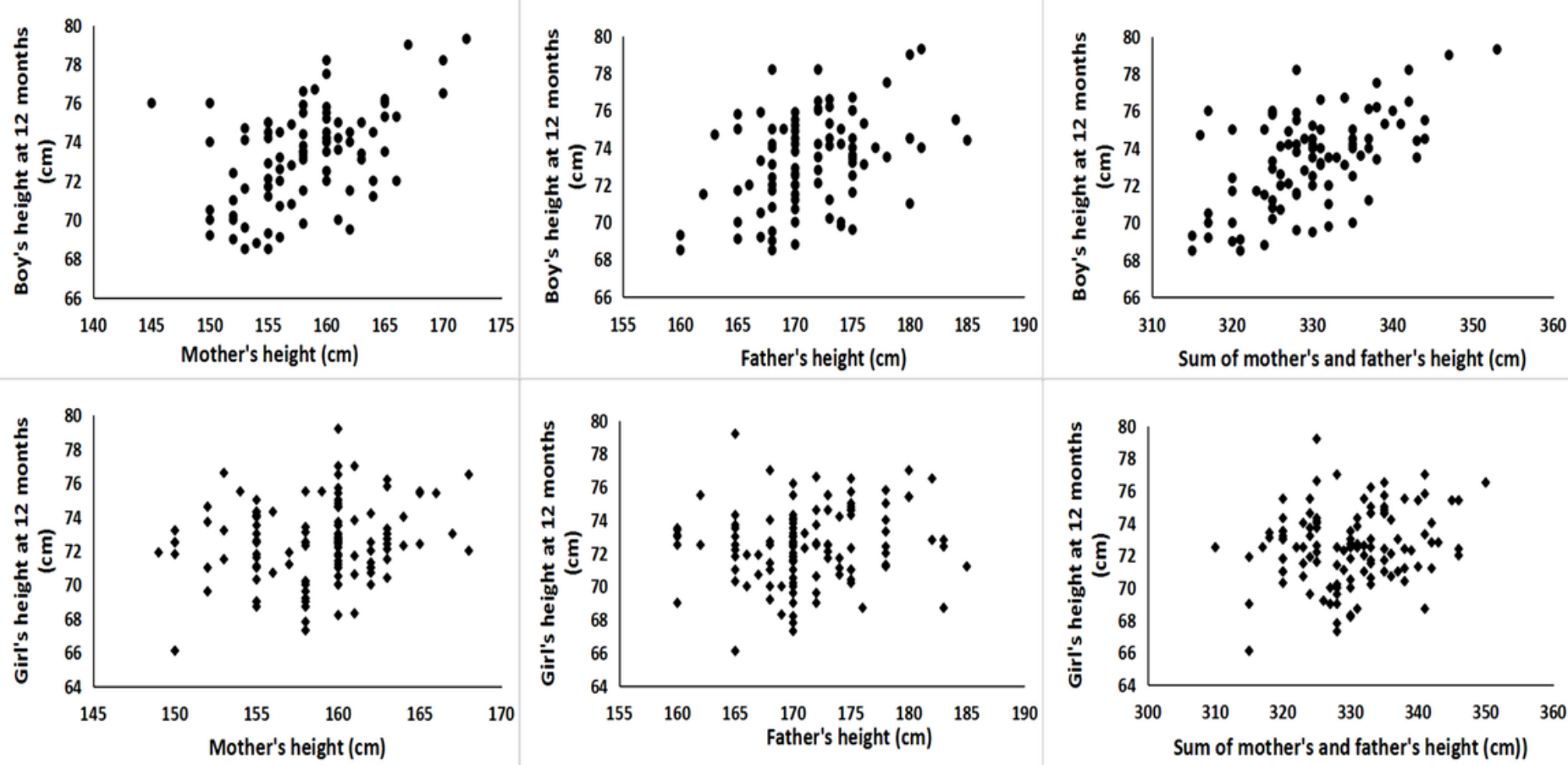

Figure 2

Scatter plots. 